Article

\title{
An Experimental Study on Alkali Silica Reaction of Concrete Specimen Using Steel Slag as Aggregate
}

\author{
So Yeong Choi ${ }^{1}$ and Eun Ik Yang ${ }^{2, *(\mathbb{D})}$ \\ 1 Research Institute for Disaster Prevention, Gangneung-Wonju National University, Gangneung-si, \\ Gangwon-do 25457, Korea; csy7510@gwnu.ac.kr \\ 2 Department of Civil Engineering, Gangneung-Wonju National University, Gangneung-si, \\ Gangwon-do 25457, Korea \\ * Correspondence: eiyang@gwnu.ac.kr; Tel.: +82-33-640-2418
}

Received: 24 August 2020; Accepted: 23 September 2020; Published: 25 September 2020

\begin{abstract}
In this study, the characteristics of the alkali-silica reaction (ASR) expansion of steel slag itself, mortar bars, and concrete specimens using steel slag as aggregate are individually investigated by the expansion test method, to determine if steel slag aggregate in concrete can provide volume stability. The results show that when steel slag is aged in water for one month, its self-expansibility is below the permitted limit of 1.5\% according to the JIS A 5015 standard. The ASR test results show that the ASR expansion of the mortar bars continuously increased with the increase in the test period. However, all mortar bars were below the permitted limit of $0.1 \%$ after 14 days according to the ASTM C 1260 standard. In contrast, the ASR expansion of concrete specimens was above the criteria prescribed by the ASTM C 1293 standard. From the results, the expansion of concrete specimens could not be controlled within the permitted limit by the ASTM 1293 criteria, even if the expansivity of steel slag did not exceed the criteria. Meanwhile, considering the crack propagation patterns of the concrete specimens, the cracks due to ASR expansion developed and connected even when the expansion was below the permitted limit. Besides, when mineral admixtures were used as the binder in the concrete specimens, there were discrepancies in the results between the expansion rate and the crack properties, such as maximum length and total crack length. Therefore, to accurately determine the change in volume due to ASR expansion in concrete using steel slag as coarse aggregate, it is necessary to check the crack patterns in addition to evaluating the expansion rate.
\end{abstract}

Keywords: expansion properties; steel slag; immersion expansion in water; alkali-silica reaction (ASR); concrete expansion due to ASR

\section{Introduction}

Concrete is one of the most widely used construction materials. It has excellent properties, such as durability, versatility, and low cost, and, it is made up of basic ingredients such as a binder, aggregate, and water. However, the massive demand for concrete over the past few decades has led to the depletion of natural sources of aggregate. To address this shortage, the development of concrete using recycled aggregate has become a vital urban sustainability project. To satisfy the demands for stronger and more durable concrete structures, extensive research on using industrial wastes as aggregate is underway.

Example of typically in a recycled aggregate, steel slag is a waste product that is generated during the production of steel and makes up nearly $15-20 \%$ of the total amount of steel produced, by weight [1]. It is rapidly becoming an important construction material in sustainable development. Steel slag as aggregate in concrete provides several benefits such as improved strength, radiation shielding, and greater resistance to acid attack than conventional concrete [2-4]. However, steel slag 
can cause expansion or cracks after backfilling [5], and cannot be reused as aggregate as it contains free calcium oxide (i.e., $\mathrm{f}-\mathrm{CaO}$ ) that causes expansion [6,7]. F-CaO combines with $\mathrm{H}_{2} \mathrm{O}$ to produce a hydrate $\mathrm{Ca}(\mathrm{OH})_{2}$, it can increase steel slag volume by $98 \%$ [8]. This volume change disturbed the development of the steel slag as a concrete ingredient. Thus, to safely use steel slag in concrete, it must be secured the volume stability $[7,9]$.

On the other hand, the stabilized method for steel slag is reforming and aging. The reforming method is to react with $\mathrm{f}-\mathrm{CaO}$ and additives such as sand, red mud, and aluminate based material as well as oxygen to the molten slag, resulting in the formation of stabilized steel slag. However, this process is used to supply additional heat to maintain the molten state of steel slag. So, this complex process is required to high cost [7]. Nevertheless, the reforming process does not affect the grade of steel, so it was needed to be secured to another stabilized method of steel slag.

The aging method by leaving in a natural state was developed in the early 1990s in Japan. However, the initial aging method takes six-month or longer, and it requires a large space. So, various studies performed to develop the acceleration aging method [10]. As a result, the comparative studies for the aging method are performed, various aging methods with low cost and high efficiency have been proposed $[7,10,11]$.

Meanwhile, durability of concrete is degraded by various chemical reactions such as carbonation, chemical erosion, alkali-silica reaction (i.e., ASR), etc. This process usually affected the materials used to make concrete. In particlar, it is well known that aggregates play an important role in the ASR $[2,12]$. Pop-out and exudation of a viscous alkali-silicate fluid are other manifestations of this phenomenon. It was first described by Stanton in 1940, in his study of cracked concrete structures by ASR [13-15]. Considering the expansion due to ASR, the range of aggregate sizes that cause the highest expansion varies with the composition of the aggregate [16]. The alkali-silica-reactivity of the aggregate may damage the concrete if no preventative measures are taken. The most accurate method of determining the ASR of an aggregate is by verifying the applicable field data. However, due to the long-term nature of this degradation phenomenon (over several decades), it is difficult to simulate under experimental conditions. Several studies have been conducted to evaluate the deterioration caused by volume changes due to ASR, using accelerated expansion methods. However, this accelerated mortar bar test method (ASTM C 1260) has several drawbacks in the evaluation of ASR $[17,18]$. Evidently, this test method misestimates ASR expansion because it uses high temperature and high hydroxide at a high temperature, and is performed over a short period of only 14 days. Furthermore, even if the ASR expansion rate is within the permitted limit after 14 days, unanticipated expansion can occur after 28 days [17]. Besides, the ASTM C 1260 test method restricts the particle size distribution of the aggregate to $5 \mathrm{~mm}$ or less. In other words, the accelerated test method is focused on the evaluation of the expansivity of aggregate using a degraded mortar bar by ASR. Consequently, there is a high possibility of a difference between the expansion in real concrete structures using coarse aggregate and that in experimental results. It is necessary to evaluate the characteristics of degraded concrete by ASR. Therefore, ASR expansion must be reevaluated using a wide-range of concrete specimens with steel slag.

In this paper, the characteristics of ASR expansion of steel slag itself, mortar bar, and concrete specimen using steel slag as aggregate are individually investigated by the expansion test method. And, the concrete propagation patterns of the concrete specimens due to ASR expansion were compared by crack mapping.

\section{Experimental Procedure}

\subsection{Materials}

\subsubsection{Binder}

Ordinary Portland Cement (OPC; ASTM Type I) was used in all the mortar and concrete specimens. To investigate the effect of mineral admixtures on the properties of ASR expansion of mortar and 
concrete specimen, a part of the cement was replaced by mineral admixture. The mineral admixtures were fly ash and blast furnace slag. The physical properties and chemical compositions of the binders are shown in Table 1. Also, the replacement ratios were 20\% for fly ash (i.e., FA20) and 30\% for blast furnace slag (i.e., BFS30), respectively.

Table 1. Physical properties and chemical compositions of the binders.

\begin{tabular}{ccccc}
\hline \hline \multirow{2}{*}{ Properties } & Binder & OPC & FA & BFS \\
\cline { 1 - 2 } Physical & Specific gravity & 3.15 & 2.19 & 2.92 \\
& Blaine $\left(\mathrm{cm}^{2} / \mathrm{g}\right)$ & 3200 & 3400 & 6300 \\
& $\mathrm{SiO}_{2}$ & 21.36 & 53.0 & 27.2 \\
& $\mathrm{Al}_{2} \mathrm{O}_{3}$ & 5.03 & 20.3 & 9.87 \\
Chemical & $\mathrm{Fe}_{2} \mathrm{O}_{3}$ & 3.31 & 10.4 & 0.51 \\
$(\%)$ & $\mathrm{CaO}$ & 63.18 & 6.57 & 53.5 \\
& $\mathrm{MgO}^{2}$ & 2.89 & 0.98 & 3.29 \\
& $\mathrm{SO}_{3}$ & 2.30 & 1.08 & 3.17 \\
& Equivalent alkalis $\left(\mathrm{Na}_{2} \mathrm{O}+0.658 \mathrm{~K}_{2} \mathrm{O}\right)$ & 0.85 & 2.58 & 0.58 \\
& Loss on ignition $(\mathrm{LOI})$ & 1.40 & 2.56 & 0.01 \\
\hline
\end{tabular}

\subsubsection{Natural Aggregates}

In conformance with the test method for determining length change of concrete due to ASR, a nonreactive fine aggregate was used to evaluate the reactivity of coarse aggregate. Additionally, the fine aggregate must satisfy certain criteria to accurately evaluate the accelerated expansion of a mortar bar, such as a fineness modulus of $2.7 \pm 0.2$. Consequently, natural sand with a specific gravity of 2.55, and a fineness modulus and the absorption ratio of 2.79 and $1.07 \%$, respectively, was used as the fine aggregate.

Crushed coarse aggregate with a maximum size of $19 \mathrm{~mm}$ was used. The specific gravity and absorption ratio of the coarse aggregate were 2.68 and $0.97 \%$, respectively. The material properties of the natural aggregates are presented in Table 2.

Table 2. Material properties of the natural aggregates.

\begin{tabular}{cccc}
\hline Type & Density (g/cm $\left.\mathbf{c m}^{\mathbf{3}}\right)$ & Absorption (\%) & Fineness Modulus (F.M.) \\
\hline Natural fine aggregate & 2.55 & 1.07 & 2.79 \\
Natural coarse aggregate & 2.68 & 1.35 & 6.6 \\
\hline
\end{tabular}

\subsubsection{Steel Slag}

We tested steel slag that is commonly available in Korea to evaluate its suitability for use as aggregate in concrete. As previously mentioned, $\mathrm{f}-\mathrm{CaO}$ combines with $\mathrm{H}_{2} \mathrm{O}$ to produce $\mathrm{Ca}(\mathrm{OH})_{2}$, which can increase the volume of the steel slag to twice its initial value [7]. Therefore, before it can be used in construction, steel slag must be treated by the aging method. Consequently, to prevent expansion due to $\mathrm{f}-\mathrm{CaO}$, the steel slag was aged in water for over a month.

\subsection{Evaluation of the Fundamental Properties of the Steel Slag}

As previously mentioned, steel slag is solid waste generated from the iron and steel industry [4]. Consequently, to use steel slag as aggregate in concrete, its fundamental properties must be investigated. In particular, we must ensure that it satisfies the required quality standards before using it in concrete. To evaluate the fundamental properties of steel slag, experiments were performed to determine its density unit weight volume, and absorption ratio, while its chemical composition was determined using X-ray fluorescence spectrometer (Philips, PW 2404, Korea Basic Science Institute, Daejeon, Korea). 
The steel slag for XRF analysis is prepared by the briquette method in which the slag is well-dried and ground into powder, which is press-formed.

\subsection{Evaluation of Expansion Properties of the Steel Slag}

\subsubsection{Immersion Expansion of the Steel Slag}

Before steel slag can be used as aggregate in concrete, an immersion expansibility test must be performed. The immersion expansion ratio of the steel slag must be below $1.5 \%$ to satisfy the required criteria. The steel slag was prepared according to the JIS A 5015 standard [19], to determine its immersion expansion using a direct method. Initially, the steel slag was immersed in water at $80^{\circ} \mathrm{C}$ for six hours, and stored in a constant temperature chamber. Subsequently, the chamber was maintained at $20{ }^{\circ} \mathrm{C}$ for eighteen hours. This process was repeated for 10 days and the steel slag volume change was determined by using a calibrated indicator (resolution: $0.01 \mathrm{~mm}$ ). It is the average of the values recorded after three iterations.

\subsubsection{Experimental Setup for the Alkali-Silica Reaction Expansion of Steel Slag}

Several studies have been performed to develop accelerated test procedures to determine the potential alkali-silica reactivity of aggregate [20]. The accelerated alkali-silica reaction test method using mortar bars was originally proposed by Oberholster and Davis in 1986 [21,22]. It is the most widely used method to evaluate the potential alkali-silica reactivity of aggregate $[17,20,21]$. Mortar bars with a water-binder (i.e., W/B) ratio of 0.47 and a sand-binder (i.e., S/B) ratio of 2.25 were fabricated. The particle size distribution of the aggregate was in conformance with the ASTM C 1260 standard [23]. The grading curves of the aggregates are shown in Figure 1.

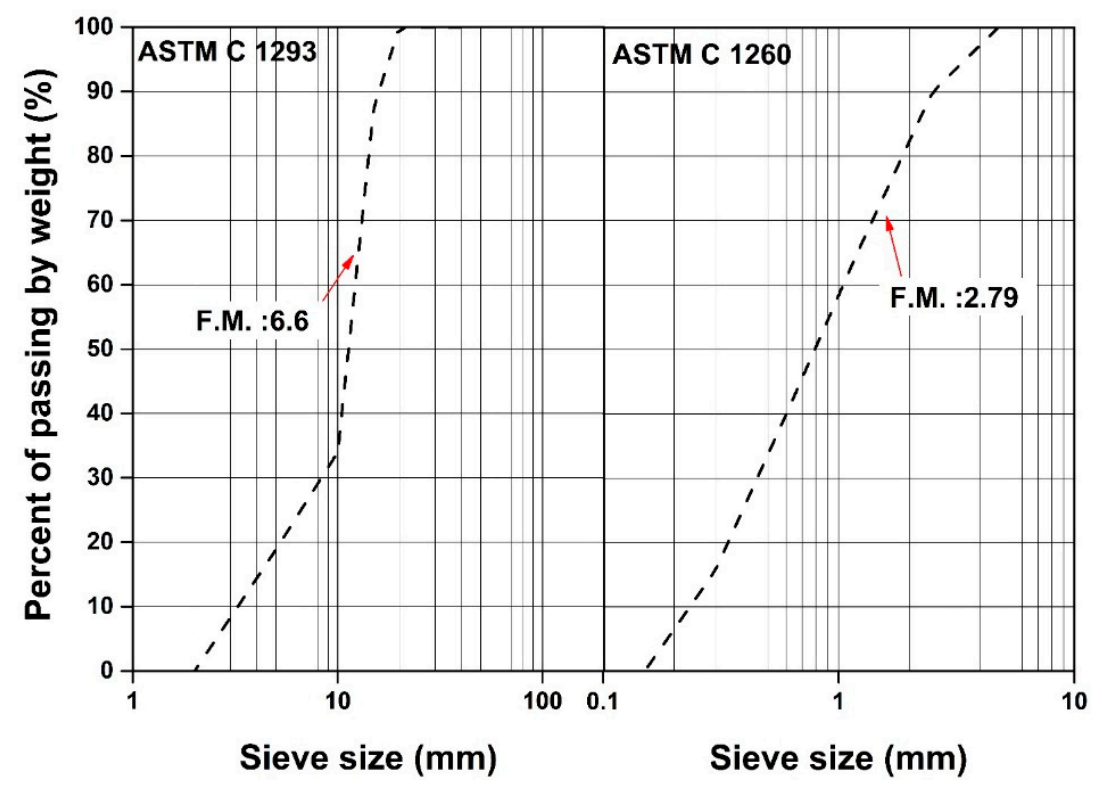

Figure 1. Grading curves of aggregate.

The standard test was performed by immersing the mortar bars in $1 \mathrm{~N} \mathrm{NaOH}$ solution at $80^{\circ} \mathrm{C}$. The prism specimens were prepared according to the ASTM C 1260 standard [23], with dimensions of $25 \mathrm{~mm} \times 25 \mathrm{~mm} \times 285 \mathrm{~mm}$. The expansion rate due to ASR was determined from the average expansion value of three specimens by using a calibrated digital indicator (resolution: $0.001 \mathrm{~mm}$ ). The test variables are listed in Table 3. 
Table 3. Test variables.

\begin{tabular}{ccc}
\hline Contents & ASR Expansion of Mortar & ASR Expansion of Concrete \\
\hline W/B ratio & 0.47 & 0.45 \\
Mineral admixture (replacement ratio) & FA $(20 \%), \mathrm{BFS}(30 \%)$ & FA $(20 \%), \mathrm{BFS}(30 \%)$ \\
Particle size distribution $(\mathrm{mm})$ & Below 4.75 & 4.75 to 19 \\
Specimen size $(\mathrm{mm})$ & $25 \times 25 \times 285$ & $76 \times 76 \times 285$ \\
Moisture condition & Immersion in solution & $100 \%$ humidity \\
Temperature $\left({ }^{\circ} \mathrm{C}\right)$ & 80 & 38 \\
Period for testing $($ days $)$ & $1,3,7,10,14$ & Until the expansion limit is reached \\
Alkali condition & $1 \mathrm{~N} \mathrm{NaOH}$ solution & Alkali content of $1.25 \%$ are added to \\
the mixing water
\end{tabular}

\subsection{Evaluation of ASR Expansion of Concrete Specimen}

ASTM C 1293 [24], a more realistic standard, was also used to determine the expansion of concrete due to ASR. This method requires the use of both coarse aggregate and fine aggregate. The coarse aggregate was graded according to the defined criteria, while the gradation of the fine aggregate was tested. The binder content was $420 \mathrm{~kg} / \mathrm{m}^{3}$ and the water-binder ratio was 0.45 . This method required the concrete specimens with dimensions of $75 \mathrm{~mm} \times 75 \mathrm{~mm} \times 285 \mathrm{~mm}$ and the alkali content of the cement to $1.25 \%$ of $\mathrm{Na}_{2} \mathrm{O}_{\text {eq }}$ by the addition of $\mathrm{NaOH}$. In this test method, the coarse aggregate and fine aggregate fractions cannot be tested simultaneously. Consequently, to evaluate the expansion due to the ASR of coarse aggregate, a non-reactive fine aggregate was used. The coarse aggregate was crushed to satisfy the particle size specifications. The criterias for ASR expansion ratio are listed in Table 4.

Table 4. Expansion criteria according to ASTM C 1260 and ASTM C 1293.

\begin{tabular}{ccc}
\hline Criteria & ASTM C 1260 & ASTM C 1293 \\
\hline Non-reactive & $0.0 \%$ to $0.1 \%$ & Below $0.04 \%$ \\
Inconclusive & $0.1 \%$ to $0.2 \%$ & \\
\cline { 3 - 3 } Potentially reactive & Above $0.2 \%$ & $0.04 \%$ \\
\hline
\end{tabular}

\section{Results and Discussion}

\subsection{Fundamental Properties of Steel Slag}

We performed various tests to evaluate the physical properties and chemical compositions of steel slag before using it as aggregate in concrete (mortar). The results and specification criteria are presented in Table 5. As shown, the density and unit weight volume of the steel slag satisfied the required criteria, however, the absorption rate was slightly higher than the value prescribed by KS F 2527 [25]. This is because the steel slag has several voids in its surface and an irregular shape. The voids and shape of the steel slag are determined by the production process of steel. A more advanced steel production technology can be used to obtain steel slag that satisfies the required criterion.

Table 5. Physical properties and chemical composition of steel slag.

\begin{tabular}{ccccc}
\hline & Content & Specification & Criteria & Test Results \\
\hline \multirow{4}{*}{ Physical properties } & Density $\left(\mathrm{g} / \mathrm{cm}^{3}\right)$ & KS F 2527 & 3.1 and above & 3.65 \\
& Unit volume weight $(\mathrm{kg} / \mathrm{L})$ & KS F 2527 & 1.6 and above & 2.2 \\
& Absorption rate $(\%)$ & KS F 2527 & Below 2.0 & 2.05 \\
Chemical & $\mathrm{CaO}(\%)$ & KS F 2527 & Below 40 & 24.4 \\
composition & $\mathrm{MgO}(\%)$ & KS F 2527 & Below 10 & 0.5 \\
& $\mathrm{FeO}(\%)$ & KS F 2527 & Below 50 & 51.5 \\
& KS F 2527 & Below 2.0 & 2.97 \\
\hline
\end{tabular}


As shown in Table 5, the content of $\mathrm{CaO}$ and $\mathrm{MgO}$ were below the specified value, however, the content of $\mathrm{FeO}$ was above it as the existing steel production process cannot smelt iron. This can be resolved by refining the steel production process.

\subsection{Evaluation Expansion Properties of Steel Slag}

\subsubsection{Immersion Expansion Properties}

The immersion expansion rate of steel slag must be below 1.5\% according to the specification value. The immersion expansion rates of steel slag and natural sand are shown in Figure 2. As shown, the expansion rates noticeably increased with the increase in the immersion period. However, the expansion rate during the immersion period was $0.048 \%$ and within the specified value of $1.5 \%$. Thus, aging the steel slag in water for a month effectively maintained the expansion limit below the required value.

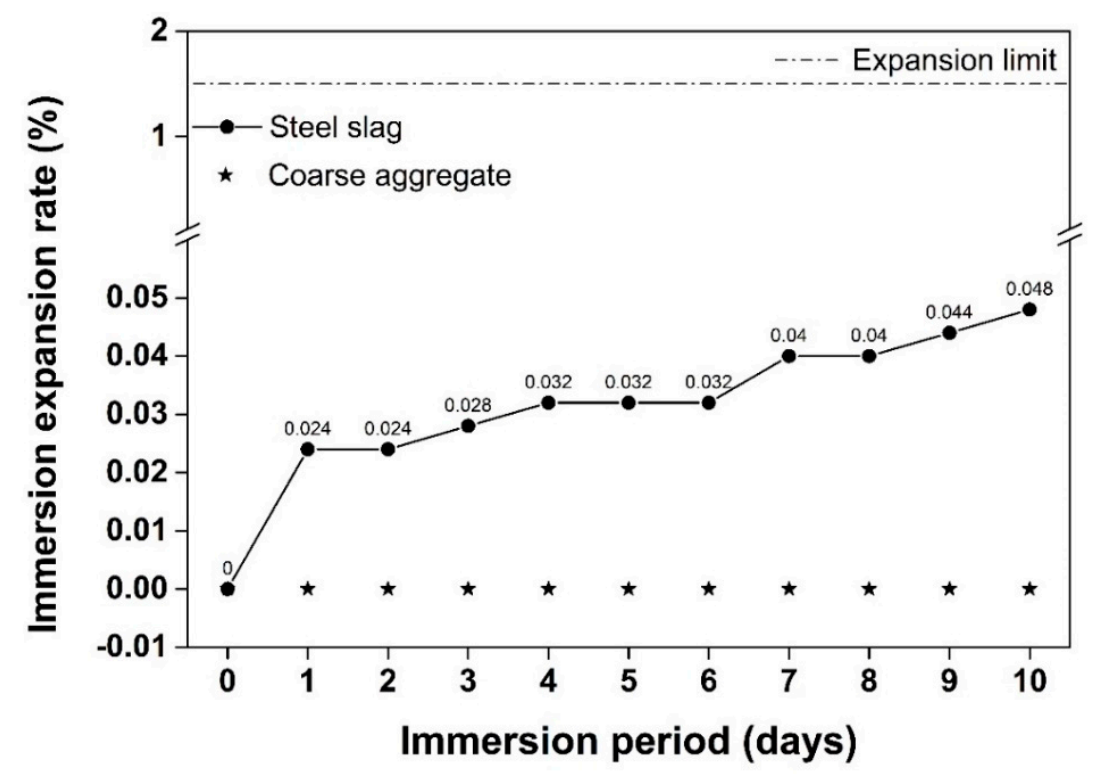

Figure 2. Immersion expansion rates of aggregate.

\subsubsection{Change in Length of Mortar Bar with Steel Slag}

The results of the ASR expansion test are shown in Figure 3. The results indicate that the expansion ratios noticeably increased with the increase in the test period. The expansion of the mortar bars with steel slag was higher than that of the mortar bars with natural aggregate. However, the expansion was within the permitted limit at 14 days, even in the specimens that only used OPC as the binder. Therefore, according to the ASTM C 1260 standard [23], both the steel slag and natural fine aggregate specimens had stable ASR expansion.

Previously studies have reported that mineral admixtures such as fly ash, blast furnace slag, and other siliceous binders can effectively reduce ASR expansion [26,27]. From Shafaatian et al. insisted that fly ash reduces the alkalinity of pore solution by reducing the ion diffusion in mortar. So, the penetration of external $\mathrm{NaOH}$ and mass transport is reduced, resulting in a lower pore fluid alkalinity, and significantly slower ASR [28]. 


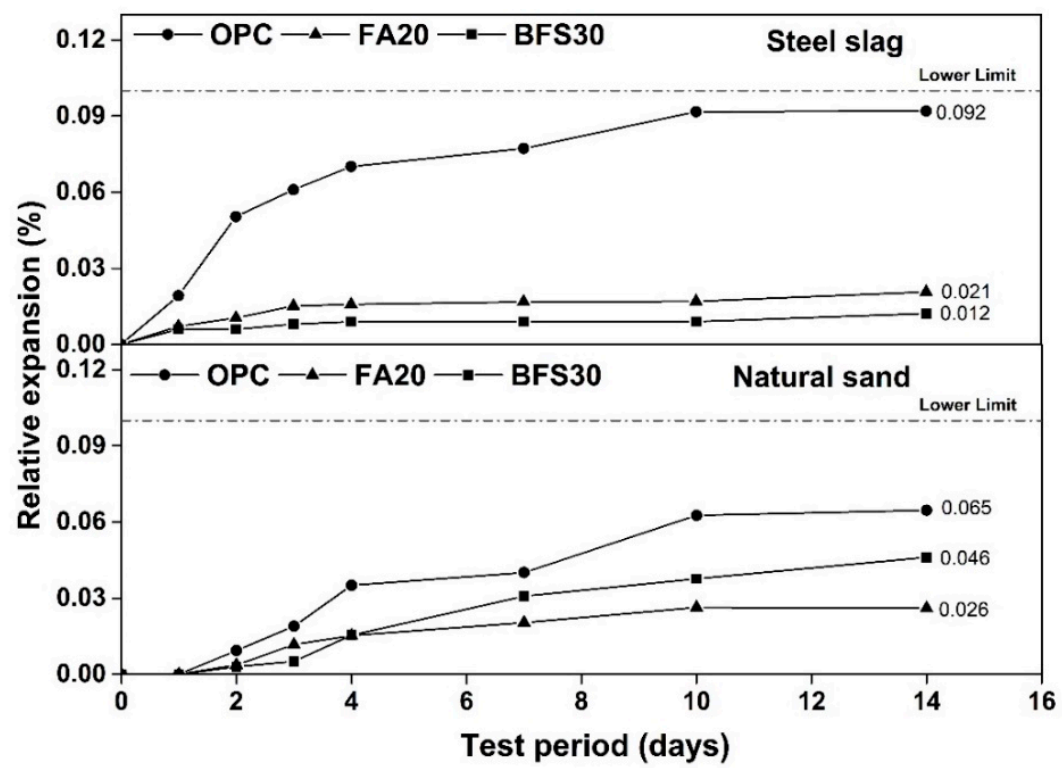

Figure 3. Results of ASR expansion test (mortar bars).

As for blast furnace slag, its hydration in cement-water systems reduces the rate of alkali diffusion to aggregate reaction sites, thereby reducing the ASR rate [29]. Blast furnace slag also has a higher specific surface area than cement and dilutes the alkali content in mortar [21,27]. In this study, we also verified the effects of mineral admixtures on ASR expansion, and the test results are shown in Figure 3. As shown, the mortar bars with mineral admixture had lesser ASR expansion. The experimental results obtained herein corroborate the findings from previous studies and show that fly ash offers a greater reduction in ASR [30] when natural sand is used as the fine aggregate. Because the pozzolanic reaction is accelerating dramatically at the high temperature and it promoted the reduction of porosity and pore size. Besides, the resistance of expansion by ASR is greater FA20 than BFS30 even if the lower replacement of FA20. In contrast, for mortar with steel slag aggregate, the reduction in ASR with blast furnace slag was greater than that with fly ash. To meet the particle size specification prescribed by ASTM C 1260 [23], the steel slag must be crushed. The crushed steel slag contains many inner cracks and surface pores. The blast furnace slag, with its high specific surface area, contributes to filling the surface pores of steel slag and improves the ASR expansion resistance of the mortar. Consequently, the expansion is affected by the aggregate and mineral admixture types, to use mineral admixture for reducing the expansion of steel slag due to ASR, the evaluation of its properties should be performed.

\subsection{Evaluation Expansion Properties of Concrete with Steel Slag}

\subsubsection{Evaluation Change in Length Concrete Specimen Due to ASR}

The relevant ASR evaluation criteria recommended the guidelines of ASTM C 1778 [31]. ASR expansion in concrete specimens using steel slag as coarse aggregate must be evaluated according to the ASTM C 1293 [24] test method. The recommended test duration using this method is more than a year, however, in this study, the experiment was stopped when the expansion exceeded the permitted limit or had converged to constant values.

The test results of the ASR expansion of two kinds of concrete specimens, one with steel slag and the other with natural coarse aggregate, are shown in Figure 4. As shown, the expansion of concrete specimens with steel slag was significantly higher than that of concrete specimens with natural aggregate. In the concrete specimens with natural aggregate, there were no noticeable differences in expansion with the different types of binder. 


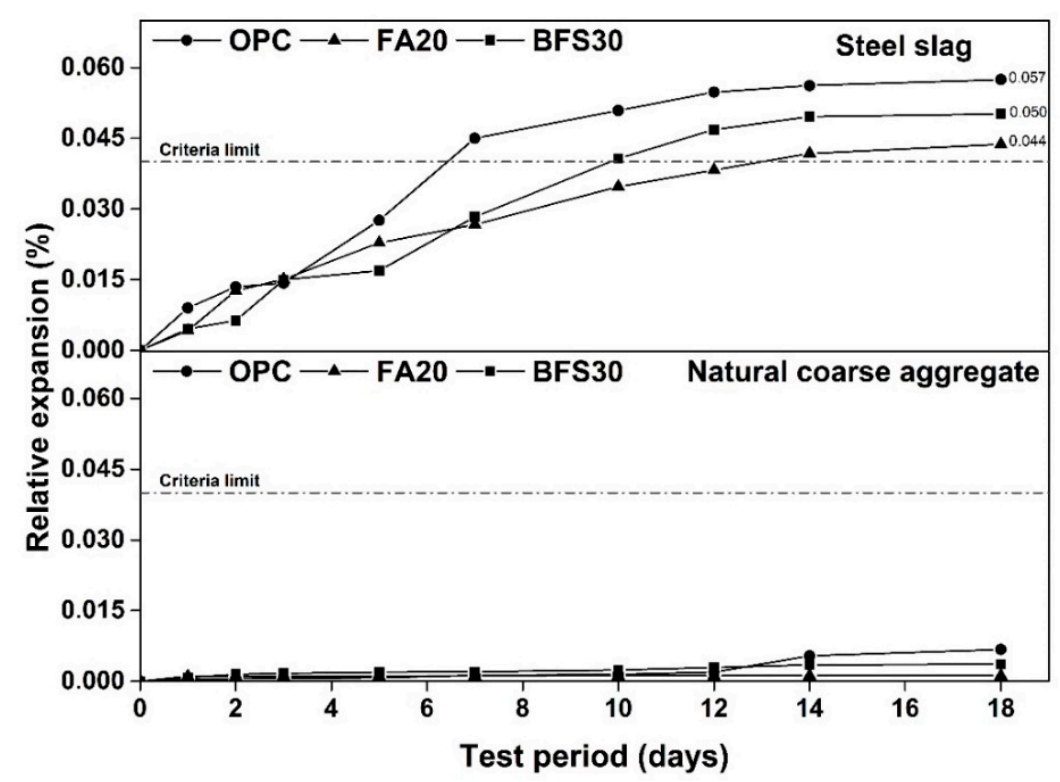

Figure 4. Results of ASR expansion (concrete specimens).

In the concrete specimens using steel slag as coarse aggregate, the expansion rate gradually increased for a 7 days of the test period. However, after 12 days, the expansion rate slowed down considerably and proceeded at a gradual rate. In the specimens with OPC as the binder, the expansion exceeded the permitted limit of $0.04 \%$ after 7 days. Furthermore, in contrast to the test results obtained using the ASTM C 1260 standard [23], the addition of mineral admixtures did not significantly reduce expansion, which exceeded the permitted limit after 10 days. Remarkably, even blast furnace slag, with its high specific surface area, was unable to sufficiently reduce and control the expansion of concrete using steel slag aggregate. Thus, considering the ASTM C 1293 [24] test results, additional methods are required to decrease the expansion of the concrete specimens.

\subsubsection{Evaluation of Crack Propagation in Concrete Specimens Due to ASR}

Cracks caused by ASR are typical non-structural cracks and are generally different from cracks caused by thermal stress or drying shrinkage. Besides, the ASR crack pattern occurs primarily in the horizontal direction [32]. In this study, we evaluated the pattern of cracks caused by ASR in the concrete specimens by drawing crack maps during the test period. The concrete specimens using natural aggregates did not exhibit any cracks due to ASR. Consequently, on the crack characteristics of the concrete specimens using steel slag were evaluated.

The typical crack progression patterns recorded during the test are shown in Figure 5. As shown, all concrete specimens, regardless of the type of binder, exhibited ASR cracking. Moreover, the number of cracks and their thickness increased during the test period, growing horizontally. Figure 5a shows the crack map of the concrete specimens at the time of crack initiation. Although the expansion rate was still below the permitted limit, all the concrete specimens exhibited ASR cracking. The specimen with the OPC binder experienced crack initiation earlier than the specimens with mineral admixtures, exhibiting a trend that is similar to be measured expansion rate. The expansion values of the specimens with FA20 and BFS30 were similar after 3 days, however, crack initiation in the concrete with FA20 occurred earlier than that in the concrete with BFS30. Thus, BFS30 offers the highest resistance against ASR cracking in concrete specimens using steel slag aggregate. Figure $5 b$ shows the crack patterns after the first 7 days of the test period. In the specimens using OPC binder, most of the cracks after 7 days were due to expansion beyond the permitted limit. The crack patterns and expansion in the specimens with the value of FA20 and BFS30 were similar. 


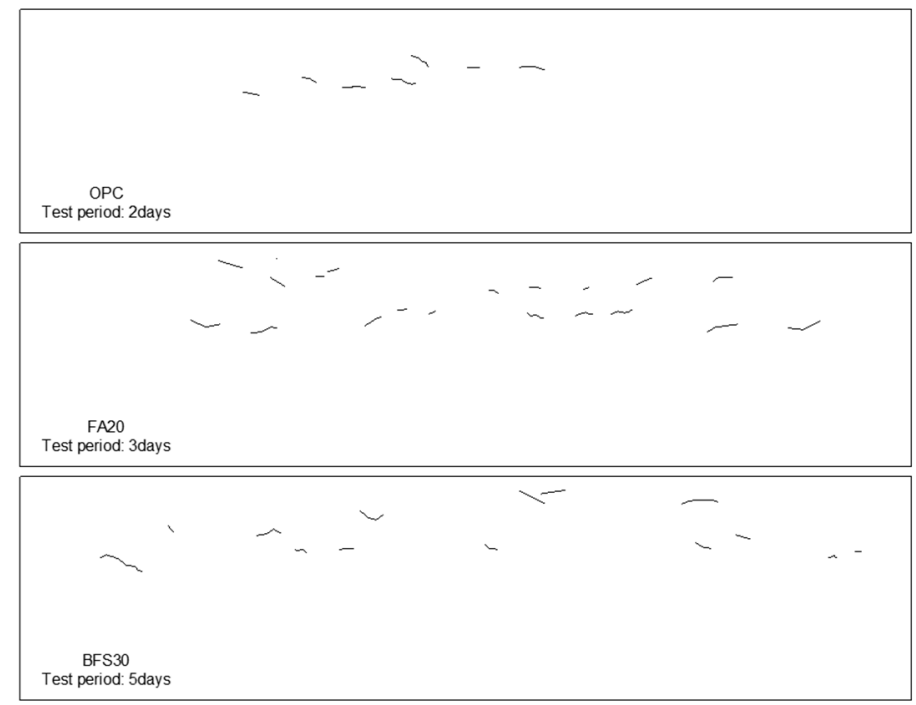

(a)
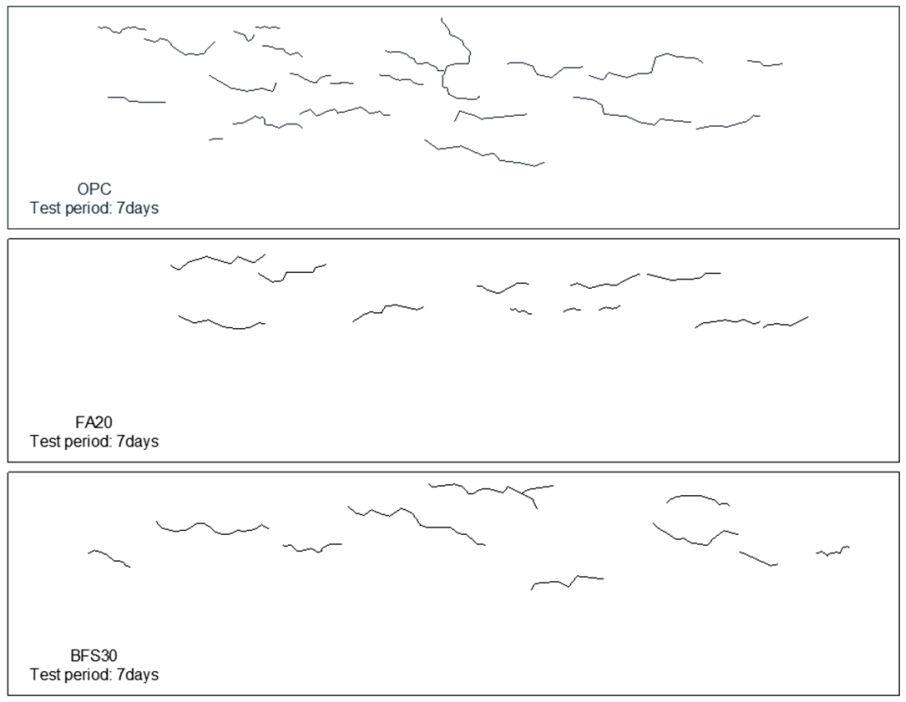

(b)
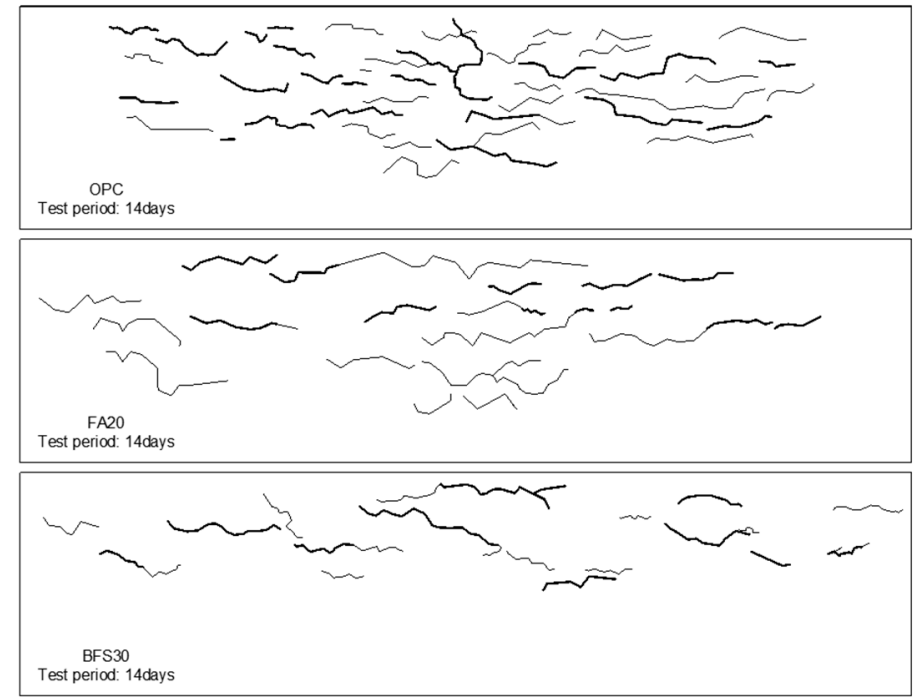

(c)

Figure 5. Crack progression patterns of concrete specimen. (a) Test period: crack initiation; (b) Test period: 7 days; (c) Test period: 14 days. 
Figure $5 \mathrm{c}$ shows the crack patterns after 14 days of the test period, when all specimens had experienced expansion beyond the permitted limit. The cracks in the surface of the specimens developed suddenly and the number of cracks increased dramatically. The existing cracks joined the newer cracks, increasing their length. In particular, the specimens with OPC showed a typical concrete surface with developed ASR cracking, wherein cracks tend to occur in a polygonal pattern.

\subsubsection{Evaluation of Crack Number and Crack Width in Concrete Specimens Due to ASR}

We evaluated the number of cracks and their width to investigate the crack patterns due to ASR. Table 6 shows the number of cracks, the crack width, the maximum crack length, and the total crack length in the surface of the concrete specimens. The cracks in concrete specimen were retraced on the Auto CAD program for calculating the crack width, maximum crack length, and total crack length. The maximum and total crack lengths increased with the increase in the duration of the test period, regardless of the type of binder. Moreover, the expansion in the concrete specimens was $0.04 \%$ higher, and the maximum crack length exceeded $100 \mathrm{~mm}$ after 14 days.

Table 6. Crack properties of concrete specimens (length, width, etc.).

\begin{tabular}{cccccc}
\hline Specimen ID & $\begin{array}{c}\text { Test Period } \\
\text { (days) }\end{array}$ & $\begin{array}{c}\text { Number of } \\
\text { Cracks }\end{array}$ & $\begin{array}{c}\text { Crack Width } \\
\text { (mm) }\end{array}$ & $\begin{array}{c}\text { Maximum Crack Length } \\
\text { (mm) }\end{array}$ & $\begin{array}{c}\text { Total Crack Length } \\
\text { (mm) }\end{array}$ \\
\hline \multirow{3}{*}{ OPC } & 2 & 7 & 0.2 & 11.59 & 63.95 \\
& 7 & 21 & 0.25 & 96.18 & 699.23 \\
FA20 & 14 & 37 & 0.4 & 173.06 & 1444.75 \\
& 3 & 19 & 0.05 & 15.57 & 158.12 \\
BFS30 & 7 & 12 & 0.2 & 47.75 & 333.30 \\
& 14 & 17 & 0.3 & 160.35 & 1031.31 \\
& 5 & 14 & 0.05 & 21.98 & 131.39 \\
& 7 & 10 & 0.15 & 71.19 & 399.13 \\
\end{tabular}

In the specimens with OPC, the number of cracks, the crack width, and the length of the cracks increased with the increase in the duration of the test period. The crack width after 14 days is higher than the allowable maximum crack width specified by ACI 224R. Currently, there is no design code for the crack limit width caused by ASR when designing the concrete structures.

Moreover, using steel slag as the coarse aggregate in concrete significantly affects ASR. Consequently, for concrete specimens using steel slag as the coarse aggregate, we must determine a method that provides improved resistance against ASR.

In contrast, in the concrete specimens with mineral admixture, the number of cracks, crack area, and crack width are decreased after 14 days as the expansion reduced. It appears that the number of cracks after 7 days were lower than the number of cracks at crack initiation. Essentially, as the cracks are developed and connected to each other, the number of cracks reduced, however, maximum crack length and total crack length is continuously increased.

While the ASR expansion was within the permitted limit defined by ASTM C 1293 [24], the maximum and total crack lengths in the specimens with BFS30 were longer than those in the specimens with FA20. However, this trend was reversed when the expansion exceeded the permitted limit. Despite the fact that the expansion rate of the concrete with FA20 was lower than that of the concrete with BFS30, the BFS30 reduced the maximum and total crack lengths after 14 days more efficiently than the FA20. This implies that the crack length is directly affected by mineral admixtures. Therefore, to accurately predict the level of deterioration due to ASR, we must not only evaluate the expansion rate but also develop indicators such as the crack pattern. 


\section{Conclusions}

The existing test methods for the evaluation of ASR expansion of concrete using steel slag as aggregate were examined. The important conclusions are as follows:

(1) To satisfy the JIS A 5015 standard of immersion expansibility of $1.5 \%$, the steel slag should be aged in water for 1 month.

(2) When steel slag used as fine aggregate in mortar bars, the ASR expansion increased with the increase in the duration of the test period. However, the ASR expansion was within the permitted limit of $0.1 \%$ after 14 days, as specified by the ASTM C 1260 standard.

(3) When steel slag was used as coarse aggregate in concrete specimens, ASR expansion could not be maintained below the permitted limit of $0.04 \%$ specified by the ASTM C 1293 standard, regardless of the presence of mineral admixtures. In addition, although the expansion rate did not exceed the permitted limit after 7 days, cracks occurred in all specimens.

(4) The evaluation of ASR expansion is affected by the mineral admixture type and the size of the steel slag. Furthermore, when mineral admixtures were used as the binder in the concrete specimens using steel slag aggregate, there were discrepancies in the results between the expansion rate and the crack properties, such as maximum length and total crack length. Thus, to accurately predict the deterioration due to ASR in concrete using steel slag as coarse aggregate, it is recommended to evaluate the expansion rate as well as to check crack patterns.

Author Contributions: S.Y.C. performed ASR test and verification of test results; E.I.Y. supported for making a research plan and performed the verification of test results; all authors contributed to the writing of this paper. All authors have read and agreed to the published version of the manuscript.

Funding: This work was supported by the Korea Institute of Energy Technology Evaluation and Planning (KETEP) grant funded by the Government of Korea (MOTIE) (No. 20171520101680).

Conflicts of Interest: The funders had no role in the design of the study; in the collection, analyses, or interpretation of data; in the writing of the manuscript, or in the decision to publish the results.

\section{References}

1. Rondi, L.; Bregoli, G.; Sorlini, S.; Cominoli, L.; Collivignarelli, C.; Plizzari, G. Concrete with EAF steel slag as aggregate: A comprehensive technical and environmental characterisation. Compos. Part B Eng. 2016, 90, 195-202. [CrossRef]

2. Wang, S.; Zhang, G.; Wang, B.; Wu, M. Mechanical strengths and durability properties of pervious concretes with blended steel slag and natural aggregate. J. Clean. Prod. 2020, 271, 122590. [CrossRef]

3. Devi, V.S.; Kumar, M.M.; Iswarya, N.; Gnanavel, B. Durability of Steel Slag Concrete under Various Exposure Conditions. Mater. Today Proc. 2020, 22, 2764-2771. [CrossRef]

4. Dhoble, Y.N.; Ahmed, S. Review on the innovative uses of steel slag for waste minimization. J. Mater. Cycles Waste Manag. 2018, 20, 1373-1382. [CrossRef]

5. Kuo, W.-T.; Shu, C.-Y. Effect of particle size and curing temperature on expansion reaction in electric arc furnace oxidizing slag aggregate concrete. Constr. Build. Mater. 2015, 94, 488-493. [CrossRef]

6. Hou, J.; Lv, Y.; Liu, J.; Wu, Q. Expansibility of cement paste with tri-component f-CaO in steel slag. Mater. Struct. 2018, 51, 113. [CrossRef]

7. Lee, H.-S.; Lim, H.-S.; Ismail, M. Quantitative evaluation of free $\mathrm{CaO}$ in electric furnace slag using the ethylene glycol method. Constr. Build. Mater. 2017, 131, 676-681. [CrossRef]

8. Siddique, R. Utilization of waste materials and by-products in producing controlled low-strength materials. Resour. Conserv. Recycl. 2009, 54, 1-8. [CrossRef]

9. Moon, H.Y.; Yoo, J.H.; Kim, S.S. A Fundamental Study on the Steel Slag Aggregate for Concrete. Geosystem Eng. 2002, 5, 38-45. [CrossRef]

10. Hamazaki, T.S.T. Development of Steam-aging Process for Steel Slag. Nippon Steel Sumitomo Met. 2015, 19, 23-26.

11. Sasaki, M.; Niida, A.; Otsuki, T.; Tsuchiya, K.; Nagao, Y. Stabilization Mechanism of Steel Slag by Aging Treatment. Tetsu-to-Hagane 1982, 68, 641-648. [CrossRef] 
12. Soltangharaei, V.; Anay, R.; Hayes, N.W.; Assi, L.N.; Le Pape, Y.; Ma, Z.J.; Ziehl, P. Damage Mechanism Evaluation of Large-Scale Concrete Structures Affected by Alkali-Silica Reaction Using Acoustic Emission. Appl. Sci. 2018, 8, 2148. [CrossRef]

13. Mehta, P.K.; Monterio, P.J.M. Concrete: Microstructure, Properties, and Materials; MC Graw-Hill: New York, NY, USA, 2014.

14. Stanton, T.E.; Porter, O.J.; Meder, L.C.; Nicol, A. California Experience with the Expansion of Concrete through Reaction between Cement and Aggregate. ACI J. Proc. 1942, 38, 209-236.

15. Stanton, T.E. Expansion of Concrete through Reaction between Cement and Aggregate. Proc. Am. Soc. Civ. Eng. 1940, 66, 1781-1812.

16. Multon, S.; Cyr, M.; Sellier, A.; Diederich, P.; Petit, L. Effects of aggregate size and alkali content on ASR expansion. Cem. Concr. Res. 2010, 40, 508-516. [CrossRef]

17. Shon, C.-S.; Zollinger, D.G.; Sarkar, S.L. Evaluation of modified ASTM C 1260 accelerated mortar bar test for alkali-silica reactivity. Cem. Concr. Res. 2002, 32, 1981-1987. [CrossRef]

18. Na, O.; Xi, Y.; Ou, E.; Saouma, V.E. The effects of alkali-silica reaction on the mechanical properties of concretes with three different types of reactive aggregate. Struct. Concr. 2016, 17, 74-83. [CrossRef]

19. Japan Standards Association. 5015. Japan Industrial Standard-Iron and Steel Slag for Road Construction; Japan Standards Association: Tokyo, Japan, 2013.

20. Lu, D.; Fournier, B.; Grattan-Bellew, P. Evaluation of accelerated test methods for determining alkali-silica reactivity of concrete aggregates. Cem. Concr. Compos. 2006, 28, 546-554. [CrossRef]

21. Davies, G.; Oberholster, R. Use of the NBRI accelerated test to evaluate the effectiveness of mineral admixtures in preventing the alkali-silica reaction. Cem. Concr. Res. 1987, 17, 97-107. [CrossRef]

22. Oberholster, R.; Davies, G. An accelerated method for testing the potential alkali reactivity of siliceous aggregates. Cem. Concr. Res. 1986, 16, 181-189. [CrossRef]

23. ASTM. ASTM Standard C1260-14, Standard Test Method for Potential Alkali Reactivity of Aggregates (Mortar-Bar Method); ASTM International: West Conshohocken, PA, USA, 2014.

24. ASTM. ASTM Standard C1293-18, Standard Test Method for Determination of Length Change of Concrete Due to Alkali-Silica Reaction; ASTM International: West Conshohocken, PA, USA, 2018.

25. Korean Standards Association. 2527. Concrete Aggregate; Korean Standards Association: Seoul, Korea, 2018. (In Korean)

26. Ramachandran, V. Alkali-aggregate expansion inhibiting admixtures. Cem. Concr. Compos. 1998, 20, $149-161$. [CrossRef]

27. Choi, S.Y.; Choi, Y.-S.; Yang, E.-I. Characteristics of volume change and heavy metal leaching in mortar specimens recycled heavyweight waste glass as fine aggregate. Constr. Build. Mater. 2018, 165, 424-433. [CrossRef]

28. Shafaatian, S.M.; Akhavan, A.; Maraghechi, H.; Rajabipour, F. How does fly ash mitigate alkali-silica reaction (ASR) in accelerated mortar bar test (ASTM C1567)? Cem. Concr. Compos. 2013, 37, 143-153. [CrossRef]

29. Klieger, P.; Lamond, J. STP169C Significance of Tests and Properties of Concrete and Concrete-Making Materials; ASTM International: West Conshohocken, PA, USA, 1994.

30. Ayub, T.; Shafiq, N.; Khan, S.U.; Nuruddin, M. Durability of Concrete with Different Mineral Admixtures: A Review. Int. J. Civ. Sci. Eng. 2013, 7, 199-210.

31. ASTM International. ASTM_C1778-14, Standard Guide for Reducing the Risk of Deleterious Alkali-Aggregate Reaction in Concrete; ASTM International: West Conshohocken, PA, USA, 2014.

32. Ian Sims, A.B.P. Alkali-Aggregate Reaction in Concrete: A World Review; CRC Press: Boca Raton, FL, USA, 2017.

(C) 2020 by the authors. Licensee MDPI, Basel, Switzerland. This article is an open access article distributed under the terms and conditions of the Creative Commons Attribution (CC BY) license (http://creativecommons.org/licenses/by/4.0/). 